\title{
Epidemiology of MTP in a tertiary care center over a period of 3 years
}

\author{
Bhawna Sharma*, Namrata Saxena, Anshu sharma, Neetu Arora
}

\begin{abstract}
Department of Obstetrics and Gynecology, Shri Guru Ram Rai Institute of Medical and Health Sciences, Patel Nagar
\end{abstract} Dehradun, Uttarakhand, India

Received: 17 August 2017

Revised: 28 August 2017

Accepted: 16 September 2017

\author{
*Correspondence: \\ Dr. Bhawna Sharma, \\ E-mail: bsbhawna@gmail.com
}

Copyright: (C) the author(s), publisher and licensee Medip Academy. This is an open-access article distributed under the terms of the Creative Commons Attribution Non-Commercial License, which permits unrestricted non-commercial use, distribution, and reproduction in any medium, provided the original work is properly cited.

\begin{abstract}
Background: Medical termination of pregnancy was legalized in India under the MTP act of 1971 which states that all the women can legally have an abortion up to 20 weeks of gestation if indicated. This study is a retrospective analysis of incidence, indication, the age group availing the facility, socio-demographic and obstetric profile of MTP seekers and the method of contraception followed after MTP.

Methods: A retrospective 3-year data was analyzed by MTP register of the hospital as a reference.

Results: The incidence rate of MTP is 96/1000 live births in the institute. The main reason for MTP is failure of contraception which highlights the unmet need of contraception and counselling. Majority of the age group availing MTP belonged to 16-20 years. Most of the women were from urban slums, were illiterate and belonged to class IV and V according to Prasad's classification. Mostly MTP seekers were parous, having $\geq 2$ living children, and maximum no. of them went to private hospitals for their previous MTP. Medical method was the most favoured method of the care giver as well as of the patient. OCP was the choice of contraception after MTP. Religious difference is still very evident in availing MTP services which can be minimized by tactful counselling.

Conclusion: MTP act of 1971 opened new horizons for the unwanted pregnancies. Young population opting for MTP indicates the unmet need of contraception and counselling suggesting that implementation and integration of MTP services should be at the root level.
\end{abstract}

Keywords: Contraception, MTP, OCP

\section{INTRODUCTION}

In India, medical termination of pregnancy was legalized in 1971 (MTP Act 1971) under which a woman can undergo abortion legally up to 20 weeks of gestation if pregnancy involves grave injury to the physical and mental health of pregnant woman substantial risk of child being born with physical and mental abnormalities, pregnancy caused by rape and failure of contraception. In 1996-1997 about 465,705 abortions were reported nationally according to ministry of health and family welfare. ${ }^{1}$ However 6.7 million unreported abortions were estimated each year which were performed by untrained persons working outside registered and government recognized institutions. ${ }^{2}$ Despite legalization of abortions in India 46 years back which resulted from intensive national campaign for safe motherhood and attention to unsafe abortion in 1960 and early 70, the practice of unsafe alternatives is tremendous. $13 \%$ of maternal deaths worldwide are due to unsafe abortions. ${ }^{3}$ In India itself the estimated maternal deaths due to unsafe abortions was $13 \%$ in $1995 .{ }^{4}$ In the last decade policy makers and administrators were made to pay special attention by women's health advocates regarding the range of issues and concerns related to abortions in order to improve the (reproductive and child health) $\mathrm{RCH}$ 
programme initiated in India so as to make it a safe alternative. ${ }^{5}$ The present study is a retrospective data analysis of MTP in a government recognized establishment over 3 year period to observe the changing trends with respect to various socio economical parameters.

The aims and objectives of the present study was to find out the incidence and indication of MTP in the institution, to find the socio demographic and obstetric profile of women undergoing MTP and to evaluate the choice of contraception made after MTP

\section{METHODS}

All the patients who had undergone MTP (under the MTP Act 1971) in the institution from October 2013 to September 2016 (3-year period) were included in the study. The data was taken and compiled from the MTP register and was analyzed in terms of incidence, indications, socio-demographic and obstetric profile among the MTP seekers and method of contraception following MTP. The anonymity was maintained in the register, as it is utmost important as is legalized as the part of MTP act. All the cases of missed abortion, blighted ovum, incomplete abortion who required suction and evacuation or medical management was excluded from the study.

\section{RESULTS}

The study analysed from the data taken for a period of 3 years i.e. $1^{\text {st }}$ October 2013 to $30^{\text {th }}$ September 2016. In total, 579 candidates availed the service for medical termination of pregnancy over 3 years. Of the total 579 patients, $502(87 \%)$ patients underwent MTP in the first trimester while as $77(13 \%)$ patients requested for MTP in the second trimester (Figure 1).

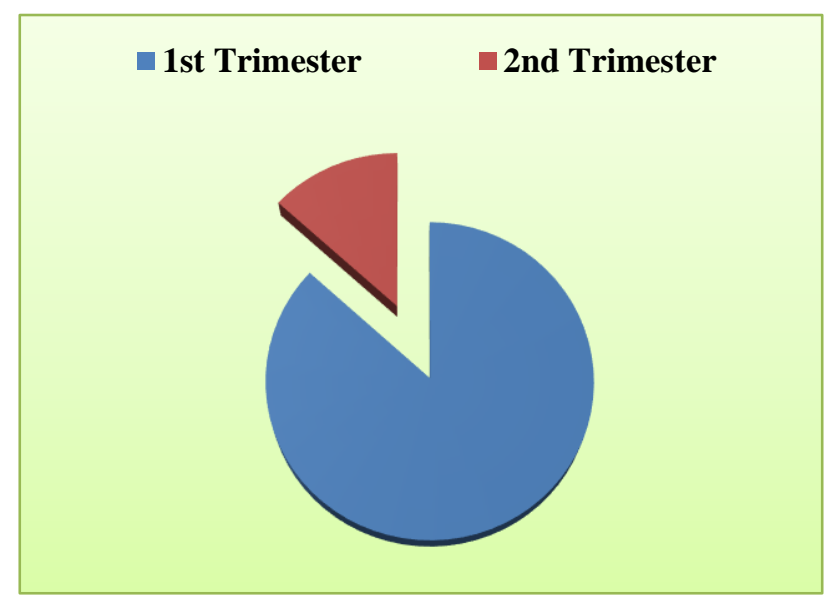

Figure 1: Trimesteric distribution of MTP.

The reason for MTP in majority i.e. $482(83.2 \%)$ patients was failure of contraception. $77(13 \%)$ patients required MTP for congenital anomalies and 13 (2.24\%) patients required MTP for maternal conditions threatening the life of the mother (Figure 2).

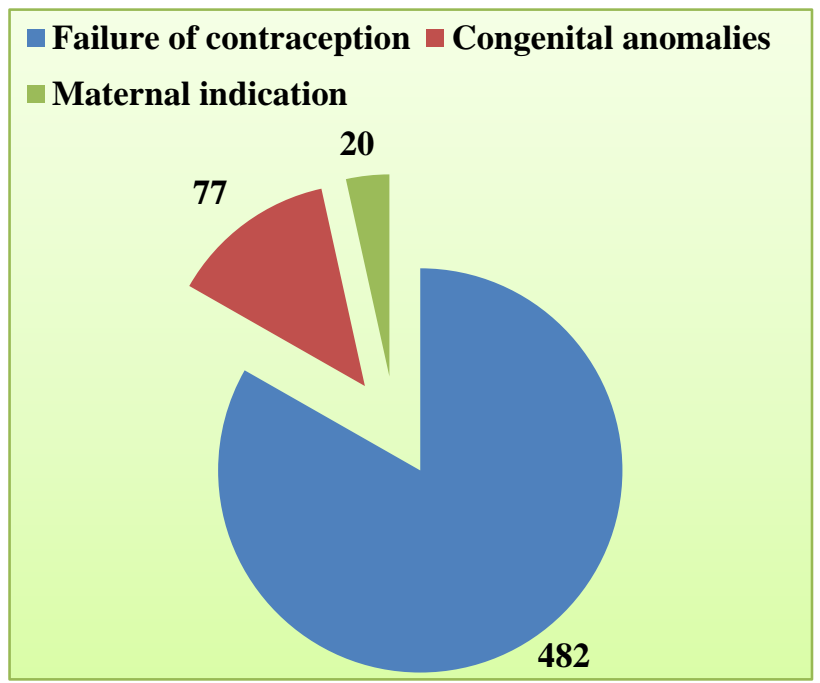

Figure 2. Causes of MTP.

Maximum no. of patients availing MTP were from age group (16-20) i.e 252, f/b (31-40) 169, (21-30) 154. There were only 4 patients from the age group (41-50) (Figure 3).

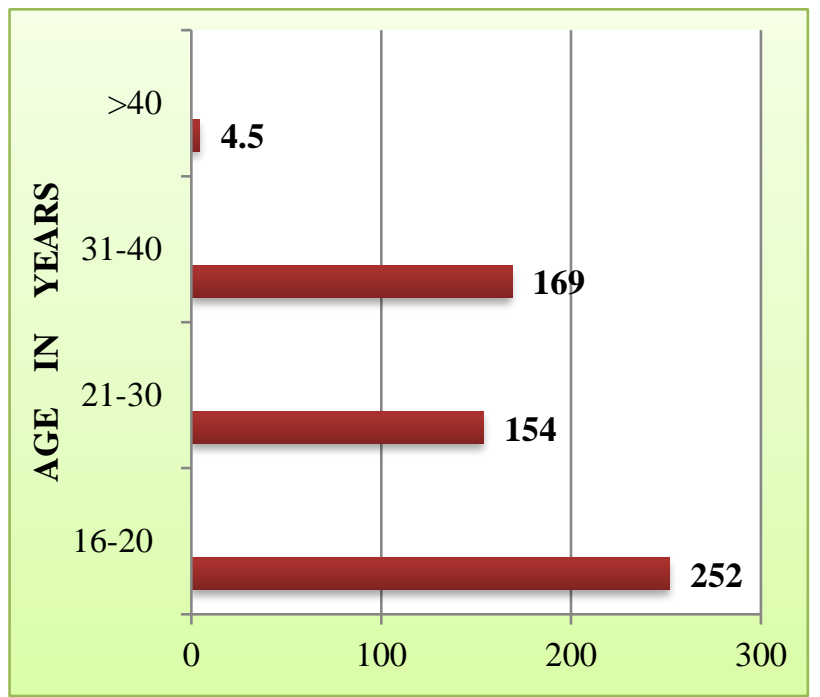

Figure 3. Distribution of age.

Majority of the patients availing the service were Hindus. Most of the patients $(88 \%)$ were successfully managed medically and only $68(12 \%)$ patients required surgical treatment (Figure 4).

Almost half of the women were from urban slums (45.9\%). $29.7 \%$ were from urban area and $24.35 \%$ were from rural area. More than $1 / 3^{\text {rd }}$ of the women were illiterate $(36.09 \%), 34.88 \%$ had primary education, $18.48 \%$ had secondary education, $6.38 \%$ had higher secondary education and only $4.14 \%$ were graduate and above. According to Prasad's classification $3 / 4^{\text {th }}$ 
(74.57\%) were from class IV and V. $21.7 \%$ were from class III, $2.7 \%$ belonged to class II and only $0.8 \%$ belonged to class 1 (Table 1).

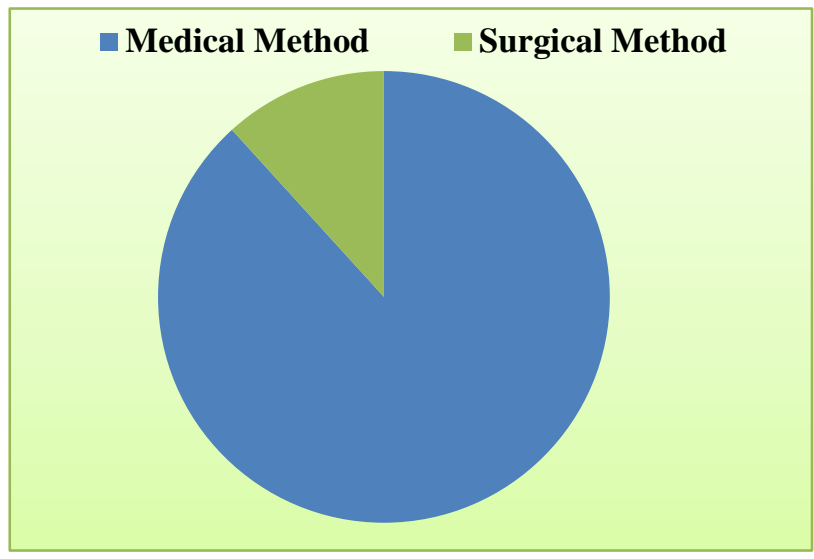

Figure 4: Method of MTP.

Majority of females opting MTP in the present study were parous having $>=2$ living children $(86.8 \%), 12 \%$ had 1 living children and only $1.2 \%$ were having no living children (Table 2).

Table 1: Socio-demographic profile of MTP seekers (based on modified Prasad's classification).

\begin{tabular}{|c|c|c|}
\hline $\begin{array}{l}\text { Socio-demographic } \\
\text { characteristics }\end{array}$ & Frequency & Percentage \\
\hline \multicolumn{3}{|l|}{ Place of residence } \\
\hline Urban & 172 & 29.7 \\
\hline Urban slum & 266 & 45.9 \\
\hline Rural & 141 & 24.35 \\
\hline \multicolumn{3}{|l|}{ Educational status } \\
\hline Illiterate & 209 & 36.09 \\
\hline Primary & 202 & 34.88 \\
\hline Secondary & 107 & 18.48 \\
\hline High secondary & 37 & 6.39 \\
\hline Graduate and above & 24 & 4.14 \\
\hline \multicolumn{3}{|l|}{ Social class } \\
\hline I & 5 & 0.8 \\
\hline II & 16 & 2.7 \\
\hline III & 126 & 21.7 \\
\hline IV & 349 & 60.27 \\
\hline V & 83 & 14.3 \\
\hline
\end{tabular}

Out of 579 women, more than half $(57.85 \%)$ went to private hospital for previous MTP, $31.7 \%$ went to government hospital and $10.3 \%$ went to unregistered (quack) (Table 3).

After the procedure maximum patients opted for OCP (262) as a secondary contraception. 73 agreed for permanent sterilization, 52 for IUCD, 90 for DMPA and there were 102 patients who did not agree for any measure of birth control (Figure 5).
Table 2: Distribution of women according to number of living children.

\begin{tabular}{|lll|}
\hline No. of living children & Frequency & Percentage \\
\hline 0 & 7 & $1.2 \%$ \\
\hline 1 & 70 & $12 \%$ \\
\hline 2 & 502 & $86.8 \%$ \\
\hline
\end{tabular}

Table 3: Distribution of women according to place of previous MTP.

\begin{tabular}{|lll|}
\hline Place of previous MTP & Frequency & Percentage \\
\hline Government hospital & 184 & $31.7 \%$ \\
\hline Private hospital & 335 & $57.85 \%$ \\
\hline Quack & 60 & $10.3 \%$ \\
\hline
\end{tabular}

Only $7.4 \%$ had knowledge of emergency contraception indicating lack of awareness (Figure 6).

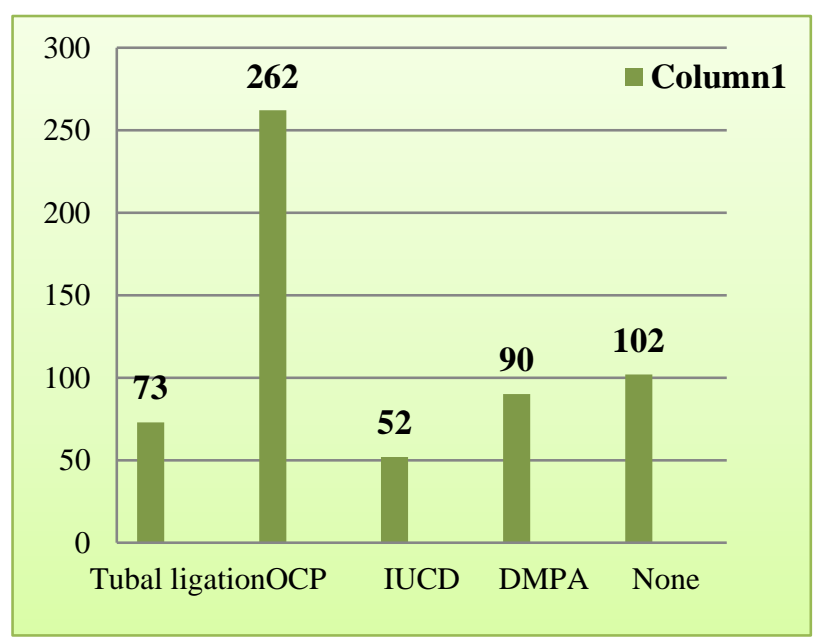

Figure 5: Secondary contraception after MTP.

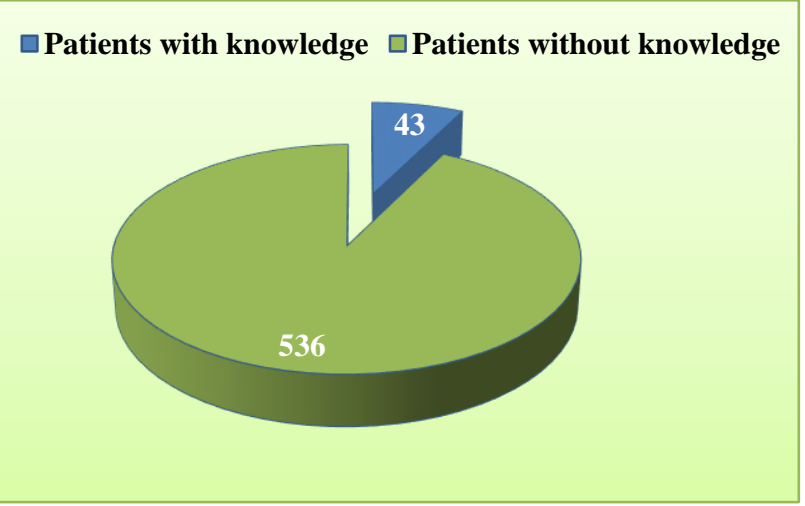

Figure 6: Distribution of women according to knowledge of emergency contraception.

\section{DISCUSSION}

Termination of pregnancy has been practiced since antiquity. Total no. of MTP in the present study for the defined duration is 579 and total no. of delivery during 
that duration is 6014 , indicating the incidence of MTP as 96 per thousand deliveries. Among total 579 cases $502(87 \%)$ were done in 1 st trimester and $77(13 \%)$ were in $2^{\text {nd }}$ trimester, which is comparable to the study of Ramesh et al where also $82 \%$ cases were done in $1^{\text {st }}$ trimester. ${ }^{6}$ The prime indication to undergo MTP in the present study was failure of contraception (83.3\%) which is comparable to the study of Katke RD et al where also the failure of contraception was the most common indication (257 cases ). ${ }^{7}$ This highlights the unmet need of contraception in the society also the need of proper counseling and uninterrupted use of method of contraception. ${ }^{8}$

$511(88 \%)$ patients in the present study were managed medically in comparison to surgical method which was conducted in $68(12 \%)$ patients in contrary to the study of Katke RD et al where surgical method was used in 221 candidates $(92.17 \%) 7$ compare to 59 cases of medical management. Choice of medical management by the care giver as well as patient's preference to be managed medically negate the complication of surgical management. However, the stay of candidate was not increased in the institute because of iatrogenic reason or due to complication of method of MTP, which suggests that the care giver is precise in selecting the candidates and is successful for implementing scientific and sterile procedure. As far as religious background is concerned, majority of the population were Hindu indicating the unawareness or non-acceptance of MTP among other religion which needs to be investigated for better implementation of health programme in the society.

Maximum no. of patients availing MTP were from age group (16-20) i.e 252, f/b (31-40) 169, (21-30) 154 There were only 4 patients from the age group 41-50. While women of all age group undergo MTP in India, a recent study suggests that majority of those seeking MTP are from age group 20-29 years of age. ${ }^{9}$ Dhillon et al in their study in 13 states in India found that maximum no. of females seeking abortions were from age group 25$34 .^{10}$

More than $1 / 3^{\text {rd }}$ of the women were illiterate $(36.09 \%)$, $34.88 \%$ had primary education, $18.48 \%$ had secondary education, $6.38 \%$ had higher secondary education and only $4.14 \%$ were graduate and above. Similarly, Ganguly et al in their study found that $44.4 \%$ females seeking MTP were illiterate, $48.2 \%$ were educated till primary school and only $7.3 \%$ cases up to high school and above. $^{11}$

Almost half of the women were from urban slums (45.9\%). 29.7\% were from urban area and $24.35 \%$ were from rural area. Mehra et al in their similar study found that $70 \%$ MTP seekers were from urban background where as $30 \%$ belonged to rural set up. ${ }^{12}$ According to Prasad's classification $3 / 4^{\text {th }}(74.57 \%)$ females were from class IV and V. Lower education and lower social status make the women more vulnerable to unwanted pregnancies and their unawareness of the safe abortion practice is an additional factor which puts them under all the possible risk of morbidity and mortality due to abortions.

Majority of females opting MTP in the present study were parous having $\geq 2$ living children $(86.8 \%), 12 \%$ had 1 living children and only $1.2 \%$ were having no living children. Ram et al in their study on unmet need of family planning among married women in Calcutta stated that there were $31 \%$ females who had 2 or less children where $69 \%$ had more than $2 .{ }^{13}$ Out of 579 women, more than half $(57.85 \%)$ went to private hospital for previous MTP, $31.7 \%$ went to government hospital and $10.3 \%$ went to unregistered persons (quack), whereas Dhillon et al found that $45.6 \%$ MTP seekers undergone MTP in a private clinic, $37.1 \%$ in hospitals, $14 \%$ in primary health center or Community health center, and "other" in $3.3 \% .^{10}$

In the present study only $7.4 \%$ women seeking MTP were aware of emergency contraception Mehra et al in their study found that only 1 patient was aware of emergency contraception while in study of Tripathi et al no patient seeking MTP was aware of emergency contraception. ${ }^{12,14}$ This implicates the fact that the role of emergency contraception should be well publicized, so as to make more and more females aware of this useful method of contraception which will definitely decrease the no. of unsafe abortions otherwise.

After the procedure maximum patients opted for OCP (262) $(45.2 \%)$ as a secondary contraception, $73(12.6 \%)$ agreed for permanent sterilization, $52(8.9 \%)$ for IUCD, $90(15.5 \%)$ for DMPA and there were $102(76.1 \%)$ patients who did not agree for any measure of birth control where as Mukhopadhyay et al, in their study on fertility regulation in Calcutta found that $35.8 \%$ accepted IUCD and $30 \%$ accepted permanent sterilization as a secondary method of contraception. ${ }^{15}$

\section{CONCLUSION}

Inadequate family planning services and unawareness of females regarding legal and safe abortions make them more vulnerable to unwanted pregnancies. Young age group is more vulnerable indicating the unmet need of contraception. Implementing and integration of abortion services at root level is the need of the hour.

Funding: No funding sources

Conflict of interest: None declared

Ethical approval: The study was approved by the Institutional Ethics Committee

\section{REFERENCES}

1. Ministry of Health and Family Welfare. Family Welfare Year Book 1997-98. New Delhi Ministry of Health and Family Welfare. 1999. 
2. Khan, ME, Rajagopal S, Barge S, Kumar N. Situational Analysis of Medical Termination of Pregnancy Services in Gujarat, Maharashtra, Tamil Nadu and Uttar Pradesh, Paper read at International Workshop on Abortion Facilities and Post-Abortion Care and Operations Research, New York. 1998:19. 21.

3. World Health Organization. Safe abortion: technical and policy guidance for health systems. Geneva WHO. 2003.

4. Registrar General of India. Medical certification of cause of death 1995. New Delhi RGI. 1999.

5. Bela G. Abortion Research in India: what we know and what we need to know, In: Ramasubban R, Jejeebhoy SJ eds, Women's Reproductive Health in India, New Delhi: Rawat Publications; 2000.

6. Ramesh AS, Sadashivaiah K, Simha JS. Medical termination of pregnancy: a study of acceptor characteristics. Bull Eugen Soc. 1981;13(3):85-90

7. Katke RD, Prabhudesai AA. Socio-epidemiological factors of medical termination of pregnancy: an overview in a tertiary care institute. Int $\mathrm{J}$ Reprod Contracept Obstet Gynecol. 2016;5(4):1061-4.

8. Banerjee NE, Sinha AL, Kriplani AL, Roy KK, Takkar DE. Factors determining the occurrence of unwanted pregnancies. Nat Med J Ind. 2001;14(4):211-4.

9. Ramasubbanand RS, Jejeebhoy J, eds, Women's Reproductive Health in India. Jaipur: Rawat Publications; 2000:186-235.
10. Dhillon BS, Chandhiok N, Kambo I, Saxena NC. Induced abortion and concurrent adoption of contraception in the rural areas of India (An ICMR task force study). Ind J Med Sci 2004;58(11):478-84.

11. Ganguly G., Biswas A., Sharma GD. Profile of women undergoing medical termination of pregnancy in hospital. J Ind Med Assoc. 1993;91(11):286-7

12. Reeti M, Poonam G, Deepti D, Anju H. Knowledge of emergency contraception among women coming for induced abortion. J Obstet Gynecol Ind. 2006;56(3):233-5.

13. Ram R, Ghosh MN, Bhattacharya S, Halder A, Chatterji C, Maskar N. Study of unmet need for family planning among married women of reproductive age attending immunization clinician medical college of Calcutta. Ind J Community Med. 2000;XXV(1):22-5.

14. Tripathi R, Rathore AM, Sachdev J. Emergency contraception: knowledge, attitude and practice among health care providers in North India. J Obstet Gynecol Ind. 2003;29:142-6.

15. Kumar MA, Anuradha G, Sebanti G, Sudhir A. Fertility regulation: 5yearstudy. J Obstet Gynecol Ind.2008;8(5):421-4.

Cite this article as: Sharma B, Saxena N, sharma A, Arora N. Epidemiology of MTP in a tertiary care center over a period of 3 years. Int J Reprod Contracept Obstet Gynecol 2017;6:4918-22. 